\title{
Two Steps to Porosity
}

\section{Key words}

porous materials

iptycenes

cross-coupling
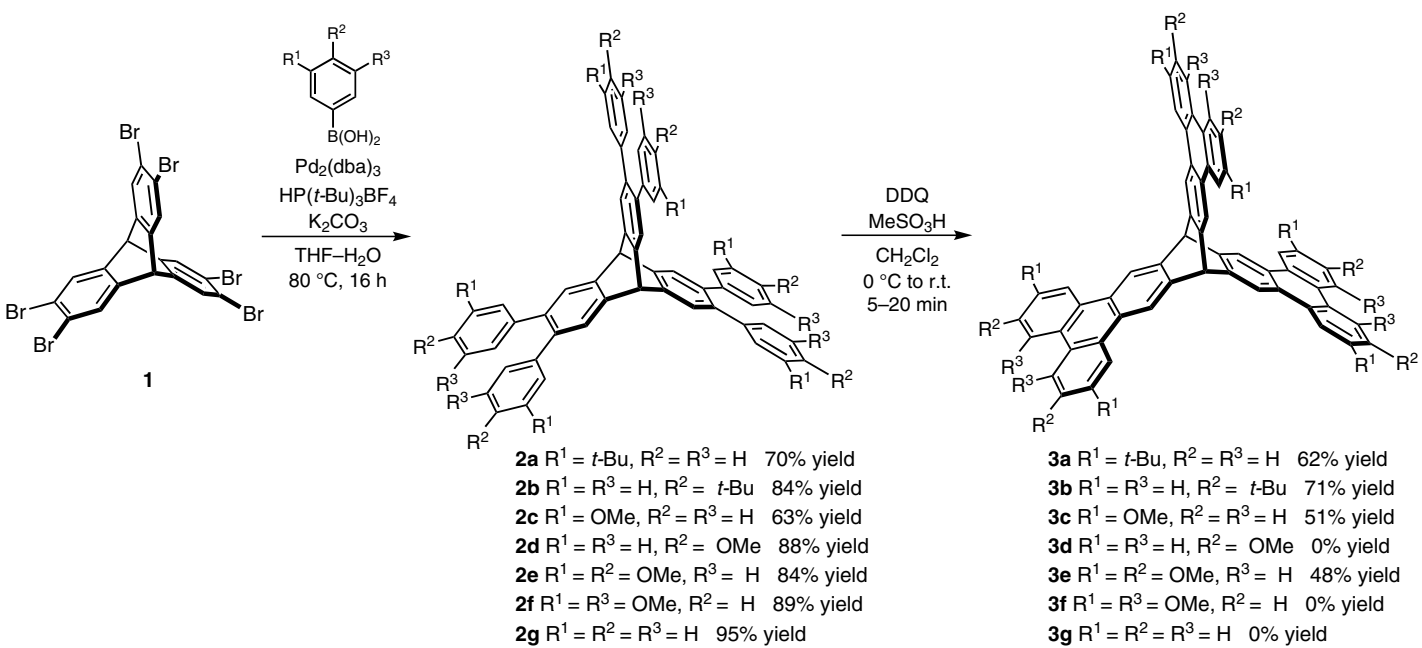

3a $\mathrm{R}^{1}=t-\mathrm{Bu}, \mathrm{R}^{2}=\mathrm{R}^{3}=\mathrm{H} \quad 62 \%$ yield 3b $\mathrm{R}^{1}=\mathrm{R}^{3}=\mathrm{H}, \mathrm{R}^{2}=t$-Bu $71 \%$ yield 3c $R^{1}=\mathrm{OMe}, \mathrm{R}^{2}=\mathrm{R}^{3}=\mathrm{H} \quad 51 \%$ yield 3d $R^{1}=R^{3}=H, R^{2}=$ OMe $0 \%$ yield 3e $R^{1}=R^{2}=$ OMe, $R^{3}=H \quad 48 \%$ yield 3f $\mathrm{R}^{1}=\mathrm{R}^{3}=\mathrm{OMe}, \mathrm{R}^{2}=\mathrm{H} \quad 0 \%$ yield $3 \mathrm{~g} \mathrm{R}^{1}=\mathrm{R}^{2}=\mathrm{R}^{3}=\mathrm{H} \quad 0 \%$ yield
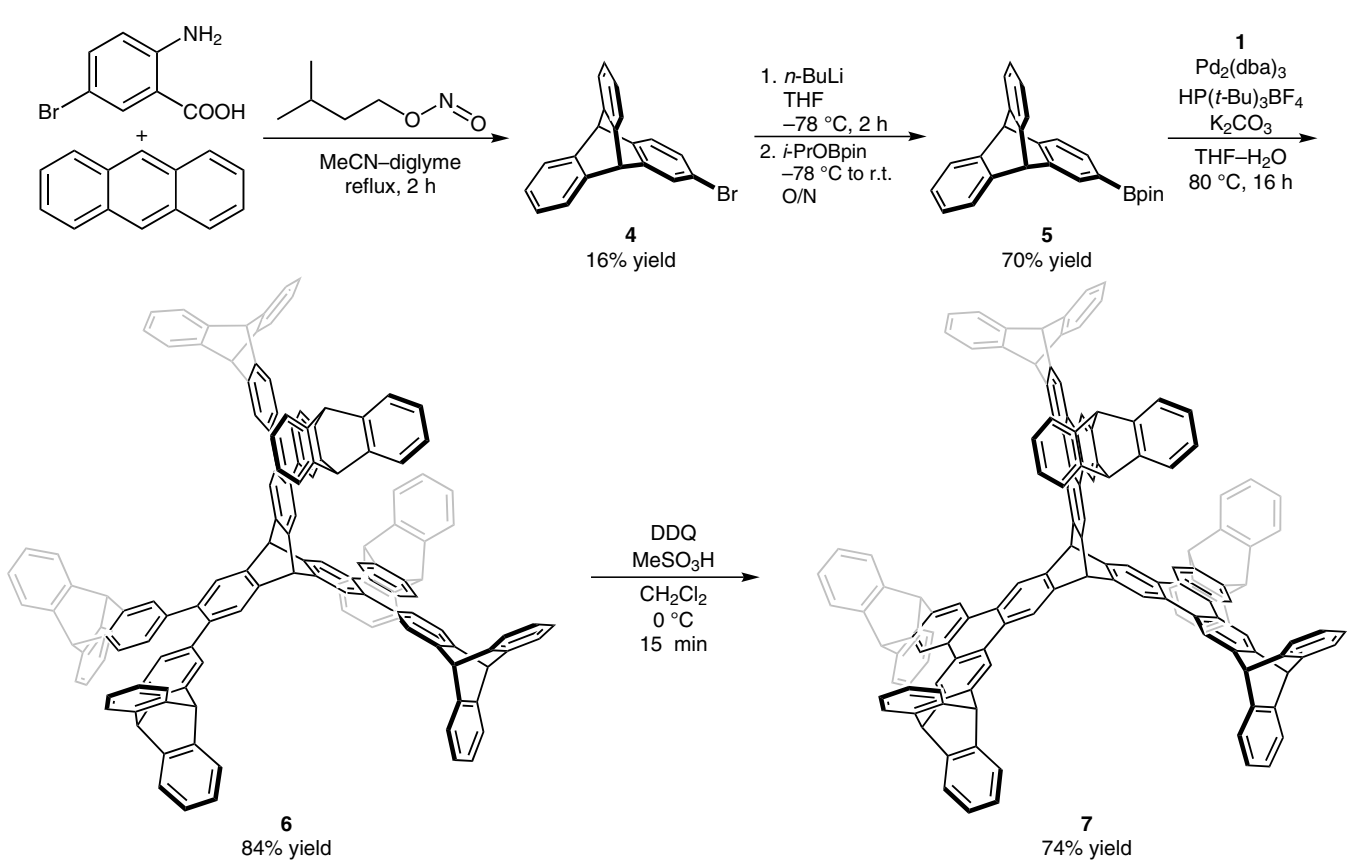

Significance: The authors describe the application of a sixfold Suzuki-Miyaura coupling on $\mathbf{1}$ followed by a Scholl oxidation to yield the corresponding triphenylenes $\mathbf{3}$. By using this method, the highly branched iptycene $\mathbf{7}$ was synthesized in four steps.

SYNFACTS Contributors: Timothy M. Swager, Jens U. Engelhart Synfacts 2015, 11(12), 1263 Published online: 17.11.2015 DOI: 10.1055/s-0035-1560957; Reg-No.: S11915SF
Comment: The success of the oxidative formation of the triphenylenes depends on the substitution pattern of the terphenylenes. Compound $\mathbf{3 g}$ could be observed but not isolated. The materials are expected to be intrinsically porous; however, absorption properties were not reported. 